\title{
DIFERENTES TÉCNICAS DE MANEJO DE PEJIBAYE (Bactris gasipaes K.) PARA PALMITO Y SUS EFECTOS EN LA PRODUCCIÓN, INCIDENCIA DE LA "BACTERIOSIS" Y DEL "PICUDO"
}

\author{
Antonio Bogantes Arias ${ }^{1}$
}

\begin{abstract}
RESUMEN
Este trabajo se realizó en la Estación Experimental Los Diamantes, ubicada en Guápiles, Costa Rica. Durante 30 meses se evaluó el efecto de cuatro densidades de siembra $(20.000,10.000,6.666$ y 5.000 plantas/ha) y dos manejos de cepa (con y sin deshija) sobre el rendimiento, la incidencia de "picudo" (Metamasius hemipterus) y "bacteriosis" (causada por los patógenos Pantoea stewarti y Fusarium sp.) en la variedad de pejibaye sin espinas Diamantes 10. Las variables evaluadas fueron: producción de palmitos, ingresos totales, porcentaje de daño por "picudo" y porcentaje de incidencia de "bacteriosis". Se observaron diferencias entre densidades, en la cantidad de palmitos cosechados para los años uno, dos y tres con una tendencia de producción curvilínea; los ingresos totales estimados fueron superiores con la densidad más alta (20.000 plantas/ha). La operación de deshija no afectó el rendimiento en el período estudiado. La incidencia de "bacteriosis", fue diferente entre densidades en todos los años evaluados, mostrándose mayor en las densidades de siembra más altas; sin embargo la deshija no afectó esta variable. En el 2003 tanto la distancia de siembra como la deshija influyeron sobre el porcentaje de cepas dañadas por picudo. En los 30 meses, el daño por picudo y la incidencia de bacteriosis tuvieron un comportamiento de tipo curvilíneo y ambos se correlacionaron en forma significativa.
\end{abstract}

Palabras claves: Bactris gasipaes, palmito, densidades, picudo, bacteriosis.

\section{INTRODUCCIÓN}

En Costa Rica, cuando inició el cultivo de palmito de pejibaye con espinas, se hicieron varias evaluaciones de densidades de siembra. A principios de la década del setenta, Camacho y Soria (citados por Mora 1989) establecieron el primer estudio experimental de pejibaye para la producción de palmito que consistió en una prueba de densidades de siembra, de la que se generó una recomendación inicial de 2.222 plantas por hectárea.

Zamora (1984) evaluó entre 1980 y 1983, distancias de siembra con plantas a "tallo simple" (eje principal y un rebrote) y "tallo doble"(eje principal y dos rebrotes) a bajas densidades, las cuales no superaron las 4.000 cepas/ha, en una época en que se comercializaba un palmito grueso.

Las recomendaciones sobre densidades de siembra, han variado a través de los años, se sembraba a 1,5 $\mathrm{m} \times 3,0 \mathrm{~m}$ lo que daba una densidad de 2.222 plantas por hectárea, también se recomendó producir palmito a distancias de $1,5 \mathrm{~m} \times 1,5 \mathrm{~m} ; 2 \mathrm{~m} \times 2 \mathrm{~m}$ y $2,5 \mathrm{~m} \times 2,5$ $\mathrm{m}$, según la topografía y la fertilidad del suelo (Fernández s. f.). Esas distancias se fueron modificando con el tiempo hasta llegar a $2 \mathrm{~m}$ $\mathrm{x} 1 \mathrm{~m}$ con una densidad de 5.000 plantas/ha, que se convirtió en la densidad estándar en el pejibaye con espinas por mucho tiempo.

1. Instituto Nacional de Innovación y Transferencia en Tecnología Agropecuaria (INTA), Costa Rica. Dirección de Investigación y Desarrollo Tecnológico. Estación Experimental Los Diamantes. 
Con respecto a las distancias de siembra, Mora (1989), señala que existen factores que obligan a variarlas, tales como: la fertilidad del suelo, el clima, las variedades, el uso de la maquinaria, el manejo agronómico o el mercado. Agrega, que la introducción de nuevas variedades es un factor que empieza a jugar un papel importante en las densidades. Así, la presencia o ausencia de espinas afecta la selección de una u otra distancia.

La densidad de siembra también influye en la práctica de deshija. En un sistema de manejo a libre crecimiento, con el tiempo la cepa llega a ser improductiva porque el aumento en el número de tallos reduce el crecimiento individual, esto justifica la deshija. Los brotes o "hijos" de la cepa o "araña", se pueden clasificar de acuerdo con su posición en: brote de cima, aquel situado sobre la araña cuyas raíces no hacen contacto con el suelo, por lo tanto debe ser podado para evitar que la cepa se encime, el brote periférico, situado en la periferia de la araña, en contacto con el suelo, es el que añade volumen a la raíz y por último, el brote radical, que surge de la raíz (Mora et al. 1999).

En lo que a las plagas y enfermedades se refiere, aunque el pejibaye para palmito se ha caracterizado por ser un cultivo rústico, los bajos precios a finales de los años 90 e inicios del 2000 estimularon el mal manejo de las plantaciones, lo cual generó un "ambiente" propicio para el desarrollo de ciertas plagas como el picudo sedoso de la caña Metamasius hemipterus sericeus (Oliv.), cuya larva se alimenta de los tejidos del tallo de la caña en descomposición, aunque ambos estadíos, larva y adulto pueden extender el daño a partes sanas (King y Saunders 1984) (Figura 1 a). Daños entre 35 y $40 \%$ a la cepa del palmito han sido indicados por Alpízar et al. (s.f.) y señalan que dicha larva puede penetrar en la base del tallo.

En el año 1999, la empresa DEMASA informó por primera vez sobre la presencia del ataque intenso de una "nueva" enfermedad en su finca con síntomas similares a los observados entre 1997-1998 en plantas de pejibaye para fruta en Tucurrique de Costa Rica y no documentados entonces. El síndrome conocido por los agricultores como "Bacteriosis del palmito", ocurre tanto en plantaciones de pejibaye para producción de palmito como para fruta, o sea en plantas jóvenes y adultas. De las plantas enfermas se aisló una bacteria y un hongo asociados (Pantoea stewarti y Fusarium sp.) aunque su relación ha sido motivo de controversia (Mora et al. 2005).

Los síntomas de la "bacteriosis" se inician con la aparición de una pequeña mancha verde más oscura de lo normal en los foliolos de la hoja y se extiende en forma longitudinal paralela a las venas del foliolo, formando una banda delgada que al extenderse se hace más notoria y cambia a color café oscuro al producir la muerte o necrosis de los tejidos afectados; en ocasiones las hojas presentan un halo de color amarillo, además de las bandas café ( $\mathrm{Fi}$ gura 1b). Las características inconfundibles de la enfermedad son una secreción gelatinosa y pústulas de color café oscuro principalmente en el lado inferior de la hoja (Mora et al. 2005).

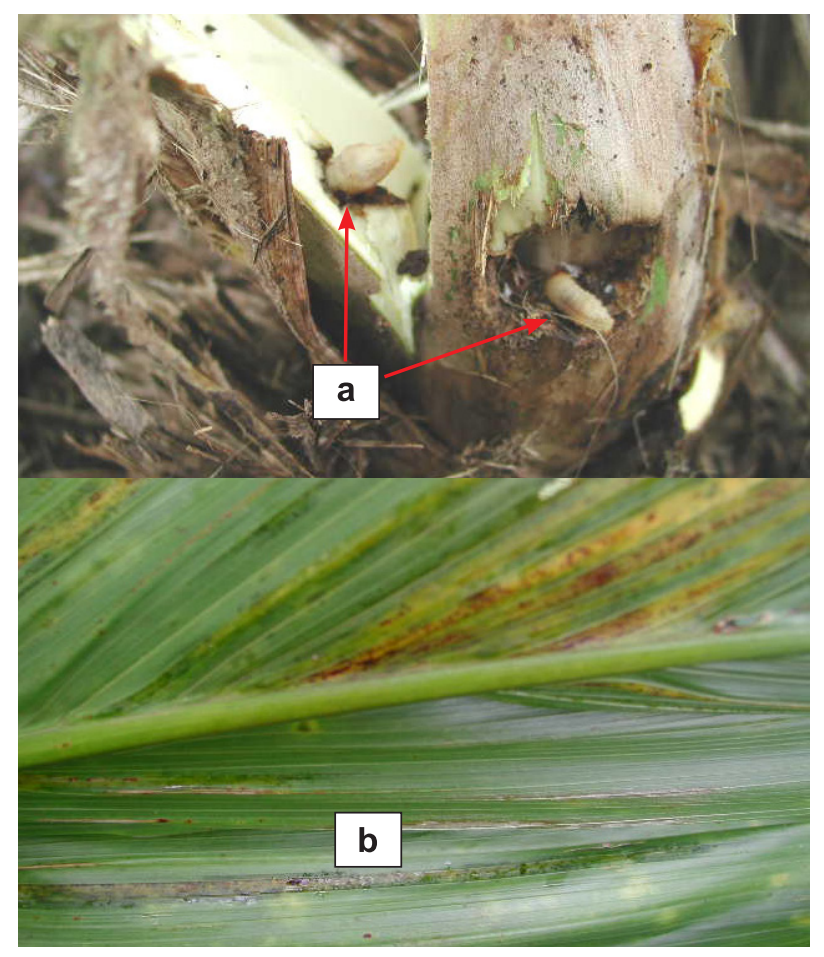

Figura 1. a) Larvas de Metamasius hemipterus y su daño, causado en la base de un tallo de palmito.

b) Síntomas de la "bacteriosis" de palmito en hoja. Guápiles, Costa Rica. 2003. 
Debido a que el mercado internacional del palmito ha mejorado en años recientes, la posibilidad de resembrar o renovar plantaciones de este cultivo ha resurgido. Además, el mayor potencial productivo de las variedades sin espinas, que permiten aumentar la densidad de siembra, brindan una nueva oportunidad de aumentar la productividad y con ello la rentabilidad, utilizando nuevas técnicas de cultivo (Mora et al. 1999). Sin embargo, se debe tener presente que a estos aspectos positivos, se une uno negativo que está representado por la aparición y extensa diseminación en el país de la enfermedad conocida como "bacteriosis del palmito". Así la realización de este estudio tuvo como objetivos: evaluar el efecto de cuatro densidades de siembra, dos estrategias de deshija sobre la producción y medir la incidencia de daño por "picudo" y "bacteriosis" en plantas de pejibaye de una variedad sin espinas.

\section{MATERIALES Y MÉTODOS}

\section{Área de estudio}

El estudio se realizó en la Estación Experimental Los Diamantes del Ministerio de Agricultura y Ganadería, ubicada en Guápiles, cantón Pococí, provincia de Limón; a una altitud de 249 msnm, con una temperatura mínima promedio de $24^{\circ} \mathrm{C}$ y una máxima promedio de $29^{\circ} \mathrm{C}$. La precipitación promedio anual es de $4.500 \mathrm{~mm}$. Se inició con la práctica de deshija en mayo del 2001 y las evaluaciones comprendieron el período entre julio del 2001 y febrero del 2004.

Se utilizó una plantación de palmito de la variedad sin espinas conocida como Diamantes 10 , con 14 meses de edad, sembrada previamente con cuatro distancias diferentes. La fertilización y el manejo de malezas se realizó siguiendo las instrucciones indicadas en el manual de recomendaciones del cultivo (Bogantes 1996).

\section{Tratamientos}

Los tratamientos evaluados fueron la combinación de cuatro distancias de siembra con dos técnicas de manejo de cepa para un total de ocho combinaciones factoriales (Cuadro 1).

La técnica con deshija consistió en eliminar los brotes de encima, hijos muy cercanos entre sí o con poco vigor y pobre sanidad. Esta práctica se hizo dos veces por año. En la técnica sin deshija no se removió ningún brote. Se practicó una limpieza general de la cepa en ambas estrategias, eliminando hojarasca u hojas viejas dos veces por año.

\section{Diseño experimental}

Se usó un diseño de parcelas divididas distribuidas en cinco bloques al azar. La estrategia de manejo de cepa se asignó a la parcela grande y las distancias de siembra entre plantas a la pequeña, para un total de 40 parcelas. Cada

Cuadro 1. Arreglo de distancias de siembra y técnicas de manejo de cepa en el cultivo de pejibaye para palmito. Guápiles, Costa Rica. 2006.

\begin{tabular}{cccc}
\hline $\begin{array}{c}\text { Distancia/hilera } \\
(\mathbf{m})\end{array}$ & $\begin{array}{c}\text { Distancia/planta } \\
(\mathbf{m})\end{array}$ & $\begin{array}{c}\text { Densidad } \\
(\text { plantas/ha) }\end{array}$ & Manejo de cepa \\
\hline 2,00 & 0,25 & 20.000 & Sin deshija \\
2,00 & 0,50 & 10.000 & Sin deshija \\
2,00 & 0,75 & 6.666 & Sin deshija \\
2,00 & 1,00 & 5.000 & Sin deshija \\
2,00 & 0,25 & 20.000 & Con deshija \\
2,00 & 0,50 & 10.000 & Con deshija \\
2,00 & 0,75 & 6.666 & Con deshija \\
2,00 & 1,00 & 5.000 & Con deshija \\
\hline
\end{tabular}


parcela pequeña midió $64 \mathrm{~m}^{2}$ y se usó una área útil de $48 \mathrm{~m}^{2}$; el área experimental total fue de $3.456 \mathrm{~m}^{2}$. Las variables evaluadas fueron:

1) Número de palmitos cosechados por parcela durante 30 meses de cosecha. Se cortaron los tallos con un promedio de $9 \mathrm{~cm}$ de grosor, medidos en la base a $10 \mathrm{~cm}$ del suelo. El palmito se dejó con dos vainas y con una longitud de $55 \mathrm{~cm}$ (abarca un máximo de $9 \mathrm{~cm}$ de palmito caulinar y $46 \mathrm{~cm}$ de palmito foliar).

2) Ingresos por venta de palmito. Se hizo una estimación para comparar los ingresos totales en dólares estadounidenses, en 30 meses de cosecha.

3) Número de plantas dañadas por "picudos". Se evaluó una vez por año $(2002,2003,2004)$ el número de plantas afectadas por larvas de picudo en la parcela total y se obtuvo el porcentaje de cepas con daño.

4) Incidencia de "bacteriosis". Se evaluó una vez por año $(2002,2003,2004)$ el número de plantas con síntomas de "bacteriosis" en la parcela total y se obtuvo el porcentaje de incidencia.

El análisis estadístico de las variables se hizo con el programa SAS (López 1995). Para el ANDEVA de las variables de daño por "picudo" e incidencia de "bacteriosis" en los años 2002 y 2004, se trabajó con información de cuatro repeticiones, mientras que en el 2003 se hizo con cinco.

\section{RESULTADOS}

\section{Producción de palmito}

La distancia entre plantas afectó el rendimiento de palmito en todos los ciclos (años) evaluados y en el acumulado (30 meses). No hubo ningún efecto de la deshija sobre el rendimiento del palmito durante esos períodos (Cuadro 2).

Durante los tres ciclos de producción así como en el rendimiento acumulado, se notó un marcado efecto de la distancia entre plantas sobre el número de palmitos cosechados por parcela, incluso en el tercer año, en el cual se evaluaron seis meses de cosecha. Cuando se aumentó la distancia entre plantas (menor densidad) disminuyó la producción de palmitos en forma curvilínea, con una tendencia a estabilizarse cuando la distancia fue de $1 \mathrm{~m}$ entre plantas. También, se manifestó una disminución general en el número de palmitos en el segundo ciclo con respecto al primero (Figura 2).

Los resultados del Cuadro 3 indican con claridad que a mayor densidad de siembra corresponde una mayor producción de palmito. Es lógico que la producción acumulada de palmitos por hectárea resulte congruente con lo indicado, ambos aumentaron conforme disminuyó la distancia entre plantas. Por lo tanto, los ingresos más altos se obtuvieron con la distancia de $0,25 \mathrm{~m}$ entre plantas, la cual muestra una diferencia positiva sobre las otras distancias $(0,50 ; 0,75$ y $1,00 \mathrm{~m})$ de 20,27 y $39 \%$, respectivamente (Cuadro 3).

Cuadro 2. Resumen del Análisis de varianza del rendimiento de palmito evaluado en cada uno de los años del estudio. Guápiles, Costa Rica. 2002-2004.

\begin{tabular}{ccccc}
\hline Fuente variación & Año 1 & Año 2 & Año 3 (6 meses) & (Acumulado) \\
\hline Distancia & $\mathrm{P}<0,0001$ & $\mathrm{P}<0,0013$ & $\mathrm{P}<0,0089$ & $\mathrm{P}<0,0001$ \\
Deshija & $\mathrm{P}=0,5426$ & $\mathrm{P}=0,6563$ & $\mathrm{P}=0,7608$ & $\mathrm{P}=0,4421$ \\
Distancia*deshija & $\mathrm{P}=0,5151$ & $\mathrm{P}=0,8707$ & $\mathrm{P}=0,1228$ & $\mathrm{P}=0,7287$ \\
\hline
\end{tabular}

$\mathrm{P}=$ probabilidad 
BOGANTES: Efectos del Manejo de pejibaye (Bactris gasipaes K.) para palmito sobre la producción, incidencia de "bacteriosis" y "picudo"
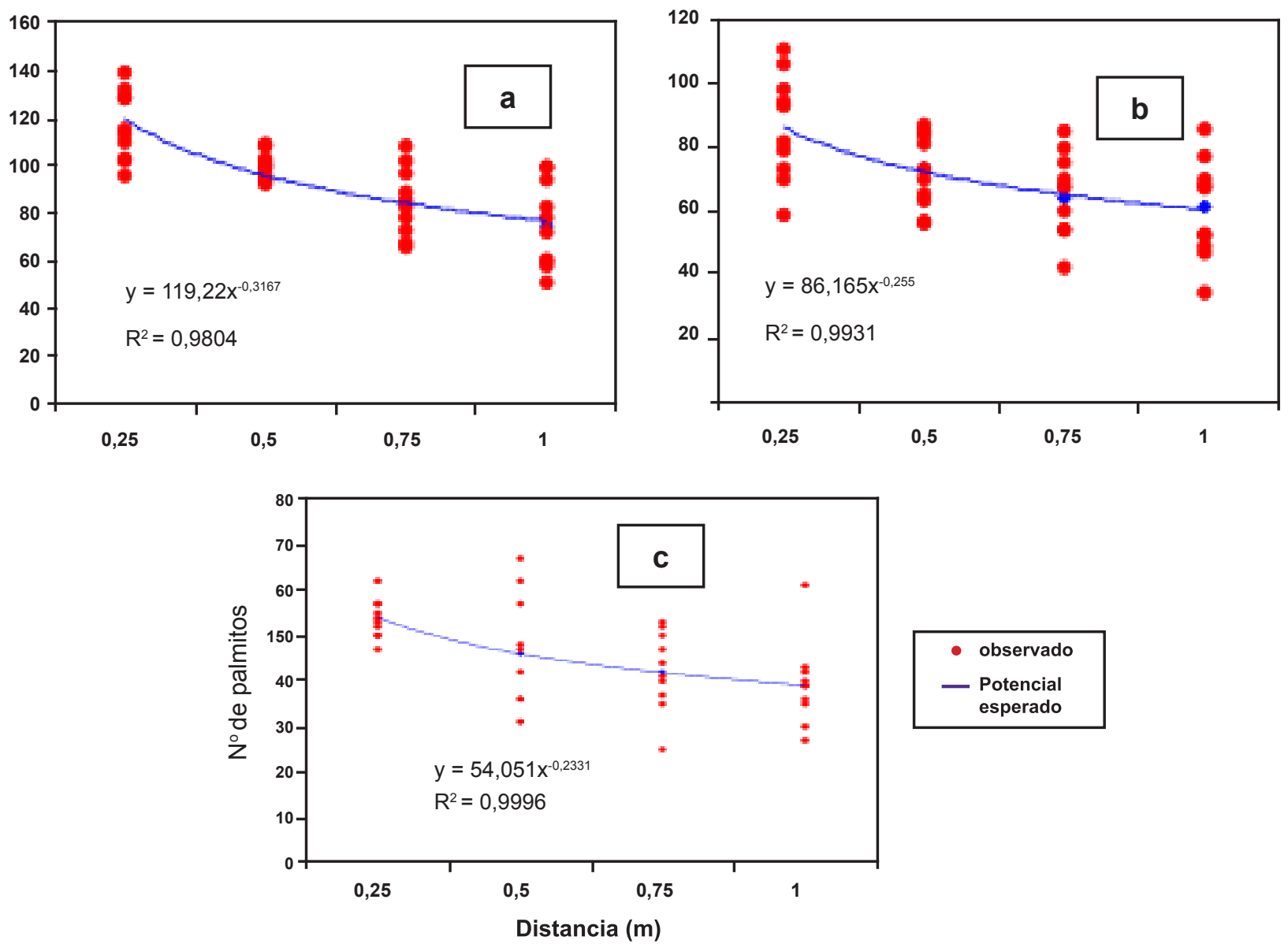

Figura 2. Producción de palmito durante los años: 1 (a), 2 (b) y 3(c). n=10. Guápiles, Costa Rica.

Cuadro 3. Efecto de la distancia de siembra sobre el rendimiento de palmito e ingresos brutos por hectárea, evaluados en 30 meses de cosecha. Guápiles, Costa Rica. 2002-2004.

\begin{tabular}{ccccc}
\hline \multirow{2}{*}{ Distancia } & Unidades/parcela & Unidades/ ha & *Ingreso/ha (\$) & Diferencia (\%) \\
\hline $0,25 \mathrm{~m}$ & 256,80 & 40.114 & 8.825 & 0 \\
$0,50 \mathrm{~m}$ & 217,50 & 32.005 & 7.052 & -20 \\
$0,75 \mathrm{~m}$ & 192,80 & 29.198 & 6.424 & -27 \\
$1,00 \mathrm{~m}$ & 175 & 24.306 & 5.347 & -39 \\
\hline
\end{tabular}

${ }^{*}$ Precio $=\$ 0,22 /$ unidad (junio-2006). 
Daño causado por picudo e incidencia de bacteriosis

Se observó un efecto negativo de la alta densidad de siembra en el primer y tercer ciclo de evaluación (2002, 2004) así como de la ausencia de deshija en el 2003 sobre el porcentaje de cepas dañadas por picudo. Con una mayor densidad y en ausencia de deshija aumentó el porcentaje de plantas atacadas, sin embargo, esto no ocurrió con la alta densidad en el segundo ciclo de evaluación (2003).

Con respecto a la incidencia de bacteriosis, ésta fue diferente entre distancias en todos los ciclos (años) evaluados y no hubo efecto de la deshija para esta variable (Cuadro 4).

Cuadro 4. Resumen del análisis de varianza para incidencia de daño por "picudo" y "bacteriosis". Guápiles, Costa Rica. 2002-2004.

\begin{tabular}{lcccccc}
\hline Fuente de Variación & \multicolumn{3}{c}{ “Picudo" } & \multicolumn{3}{c}{ "Bacteriosis" } \\
\hline Año & 2002 & 2003 & 2004 & 2002 & 2003 & 2004 \\
Distancia & $\mathrm{P}=0,27$ & $\mathrm{P}=0,02$ & $\mathrm{P}=0,19$ & $\mathrm{P}=0,07$ & $\mathrm{P}=0,04$ & $\mathrm{P}=0,06$ \\
Deshija & $\mathrm{P}=0,38$ & $\mathrm{P}=0,01$ & $\mathrm{P}=0,08$ & $\mathrm{P}=0,26$ & $\mathrm{P}=0,47$ & $\mathrm{P}=0,17$ \\
Distancia*deshija & $\mathrm{P}=0,72$ & $\mathrm{P}=0,36$ & $\mathrm{P}=0,38$ & $\mathrm{P}=0,43$ & $\mathrm{P}=0,15$ & $\mathrm{P}=0,27$ \\
\hline
\end{tabular}

$\mathrm{P}=$ probabilidad.

En los tres años, los resultados de daño por picudo y la incidencia de bacteriosis tuvieron un comportamiento de tipo curvilíneo. En el 2002 y en el 2004 el porcentaje de cepas con daño por picudo disminuyó poco al aumentar la distancia entre plantas de $0,50 \mathrm{~m}$ a $0,75 \mathrm{~m}$ pero mostró un leve aumento con la distancia de $1 \mathrm{~m}$, mientras que en el 2003 el porcentaje de plantas afectadas presentó un ligero incremento al aumentar la distancia entre plantas (Figuras 3, 4 y 5).
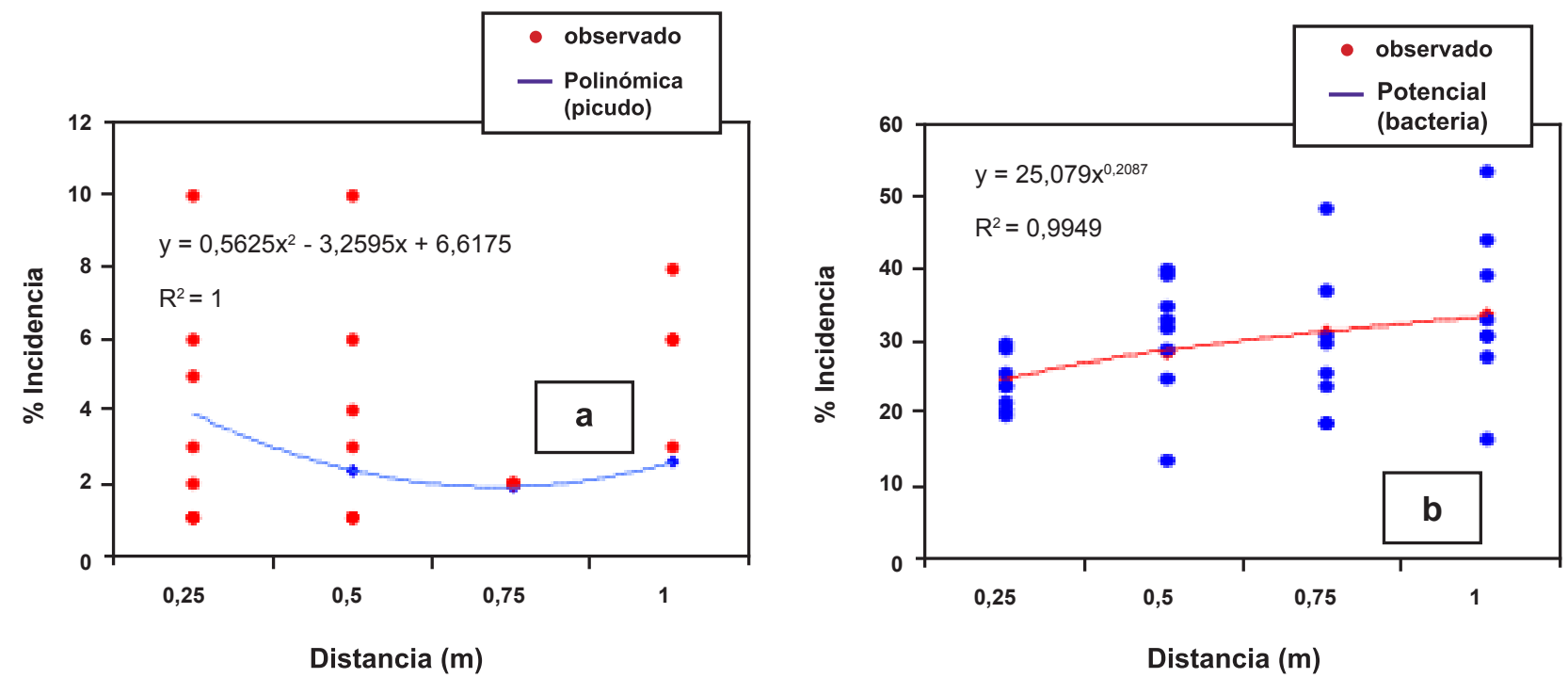

Figura 3. Porcentaje de cepas de palmito con daño de picudo (a) y bacteriosis (b) en el 2002 ( $n=8)$. Guápiles, Costa Rica. 2002-2004. 
El efecto de la deshija en el 2003 sobre la incidencia de daño por picudo, fue mayor $(p=0,011)$ en las parcelas sin deshija $(8,90 \%)$ respecto a las parcelas en las que las plantas se deshijaron $(6,85 \%)$.

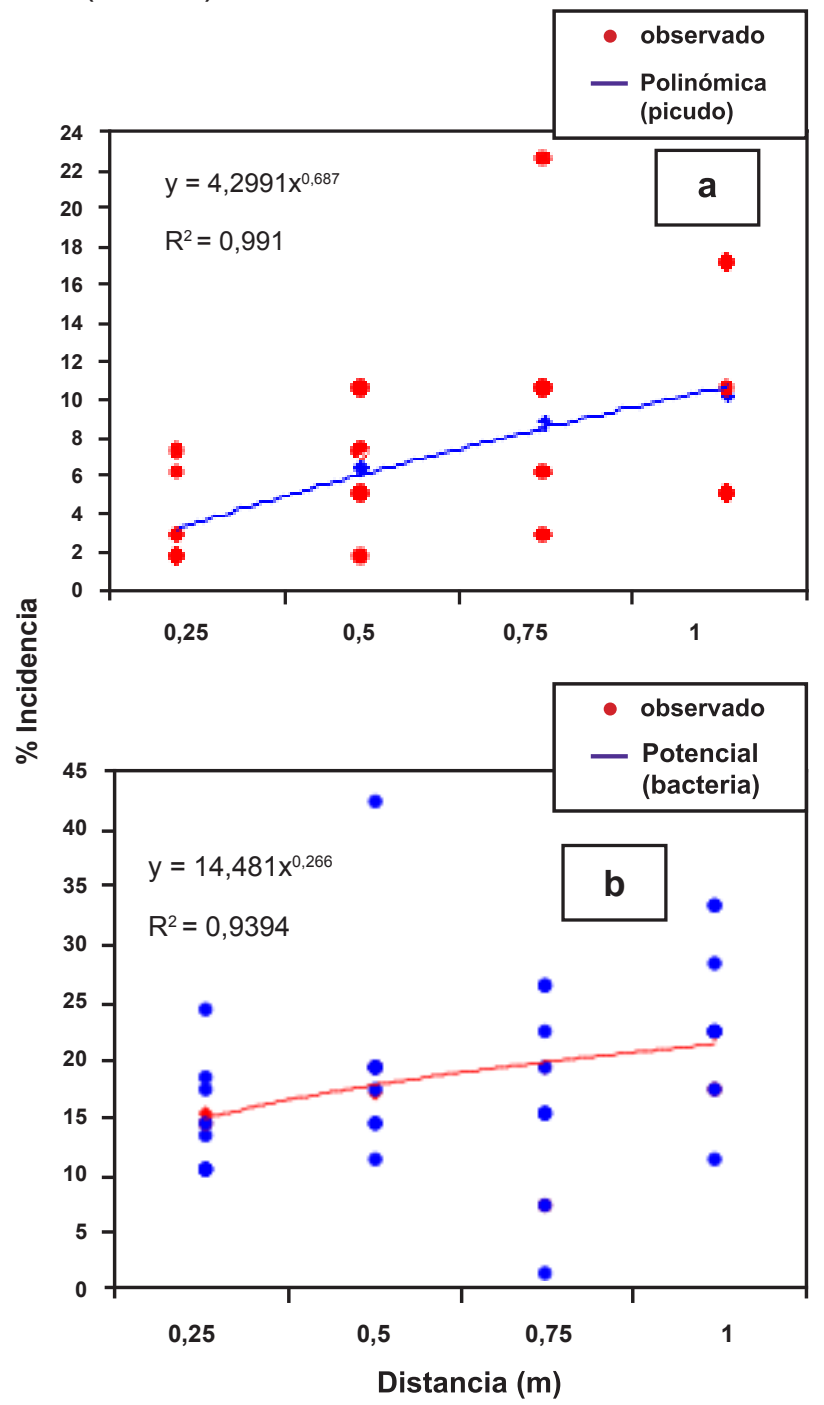

Figura 4. Porcentaje de cepas de palmito con daño de picudo (a) y bacteriosis (b) en el $2003(n=10)$. Guápiles, Costa Rica. 2002-2004.

La incidencia de "bacteriosis" en los años 2002 y 2003 presentó un leve aumento conforme aumentó la distancia de siembra mientras que en el 2004, disminuyó conforme aumentó la distancia de 0,25 a 0,50 y 0,75 m entre plantas, pero luego tuvo un ligero incremento cuando la distancia entre plantas fue de $1 \mathrm{~m}$. Así, el comportamiento de la "bacteriosis" es bastante similar al del daño por picudo, principalmente en los años 2003 y 2004 (Figuras 3, 4 y 5).

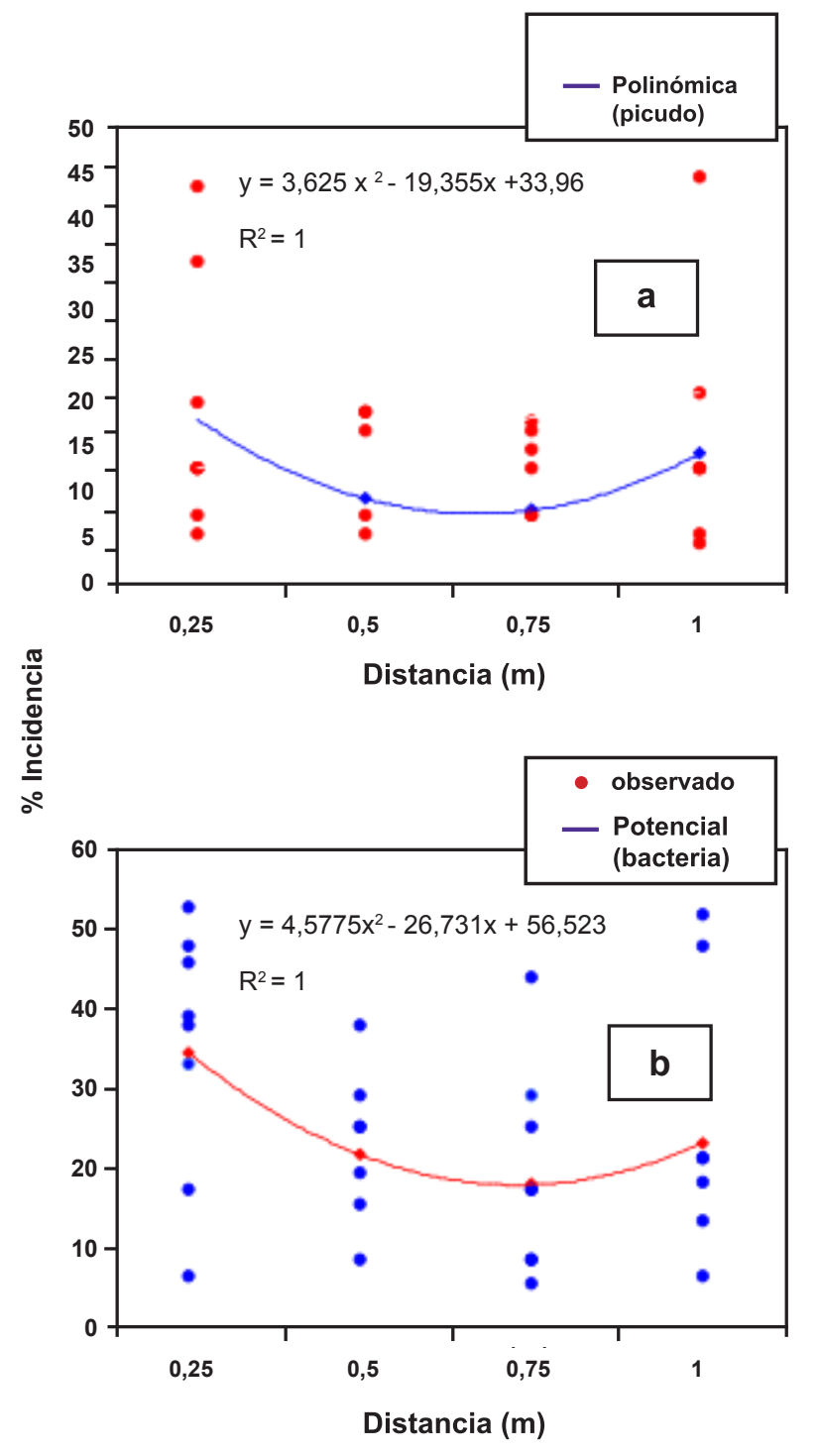

Figura 5. Porcentaje de cepas de palmito con daño de picudo (a) y bacteriosis (b) en el 2004 $(n=8)$. Guápiles, Costa Rica. 2002-2004.

Esa correlación positiva entre el porcentaje de daño por picudo y la incidencia de bacteriosis en las tres evaluaciones hechas durante los años 2002, 2003 y 2004 (Figuras 3, 4 y 5) se observa con claridad en el Cuadro 5 . Es evidente que la probabilidad ( $p$ ) de que esa correlación sea cero, es baja en la evaluación del 2002 y mucho más baja en las evaluaciones del 2003 y 2004. Lo mismo se aprecia con el coeficiente de correlación (r), el cual es relativamente bajo en el 2002 pero aumentó en el 2003 y es muy alto en la evaluación del 2004. 
Cuadro 5. Relación entre porcentaje de daño por picudo e incidencia de bacteriosis en los tres períodos evaluados. Guápiles, Costa Rica. 2002-2004.

\begin{tabular}{cccc}
\hline Año & $\begin{array}{c}\text { Coeficiente } \\
\text { de correla- } \\
\text { ción }(\mathbf{r})\end{array}$ & $\begin{array}{c}\text { Probabilidad } \\
(\mathbf{p}) \text { de } \\
\text { correlación } \\
\text { cero }\end{array}$ & $\mathbf{n}$ \\
\hline 2002 & 0,37 & 0,04 & 32 \\
2003 & 0,44 & 0,004 & 40 \\
2004 & 0,90 & 0,003 & 32 \\
\hline
\end{tabular}

\section{DISCUSIÓN}

\section{Producción de palmito}

La respuesta obtenida en el rendimiento del palmito con respecto a la densidad, concuerda con los resultados de Bogantes et al. (2004) en los primeros cuatro meses de cosecha de un experimento previo al actual y en la misma parcela. En esa prueba los autores mencionados, reportan durante los primeros cuatro meses de producción, los mejores rendimientos en número de palmitos cosechados y número de cajas de exportación con las densidades de siembra más altas. También la producción e ingresos mayores en ese período ocurrieron con la densidad más alta o sea 20.000 plantas/ ha $(2,0 \mathrm{~m} \times 0,25 \mathrm{~m})$ mientras que los valores más bajos de estas dos variables se obtuvieron en el tratamiento con 5.000 plantas/ha $(2,0 \mathrm{~m}$ $x 1,0 \mathrm{~m}$ ); resultando en un aumento del $70 \%$ en la producción e ingresos en las parcelas con menor distancia entre plantas (las de más alta densidad). Esa tendencia de producir más palmitos conforme aumenta la densidad, ya había sido reportada en varios trabajos anteriores (Zamora 1984, Chalá 1991, Vargas 1994 y 2000, Bogantes et al .1997).

Respecto a las altas densidades de siembra, Mora et al. (1999) consideran que una de las principales ventajas consiste en obtener altos rendimientos en los primeros meses o años de producción, lo cual justificaría la mayor inversión inicial, resulta claro que, en las parcelas sembradas con mayor densidad (20.000 plantas/ha) se obtuvieron los mayores ingresos por hectárea en forma proporcional en los primeros años.

Varios factores podrían contribuir a explicar por qué la deshija no afectó el rendimiento en número de palmitos. En primer lugar, la poca edad de las cepas (cuatro años) las hace menos cespitosas (menos tallos/cepa), en segundo término, la reducción del espacio por el aumento en la densidad, ya que si la cepa tiene espacio, recibe más luz que estimula la producción de nuevos brotes. Adicionalmente, ese tratamiento de deshija se efectuó sólo dos veces al año; en ese sentido, un estudio comentado por Vargas (2000), en una plantación de 14 años de edad y con 3.333 plantas por ha, determinó que conforme se incrementó el número de deshijas anuales, la producción de palmitos aumentó; en este caso se elimina el exceso de brotes que compiten entre sí por nutrientes y luz.

\section{Daño por picudo e incidencia de bacteriosis}

Mora et al. (2005) establecieron que los adultos de Metamasius se refugian en las vainas de las hojas y les agrada la oscuridad al sentirse más protegidos.

Dicha situación es relevante y hace pensar que conforme aumenta la densidad, el incremento de tallos disminuye la luminosidad, aumenta el número de hojas secas y ofrece mayor protección, la cual se refleja en la incidencia de cepas con daño por picudo en los años 2002 y 2004; aunque no así en el 2003. Norris y Kogan (2000) señalan que los cambios producto del crecimiento de un cultivo y la presencia de otras plantas, modifican de inmediato el ambiente y el grado de modificación depende de la cantidad de vegetación presente, la cual a menudo es relacionada con la edad y con la naturaleza de las especies presentes y afecta todas las especies de artrópodos.

En relación con el efecto de la poda de hijos sobre la incidencia de daño de "picudo" observado en el 2003, los resultados coinciden con los de Alpízar et al. (2002) quienes en una evaluación de daño por Metamasius y Rhyncho- 
phorus encontraron menor incidencia de daño $(15 \%)$ en las parcelas donde se deshijó la cepa con respecto a las parcelas en las que no se podó la cepa $(20 \%)$.

La incidencia de la "bacteriosis" en las diferentes distancias, tuvo un patrón similar al mostrado por "picudo" en el primer y segundo año; mientras que la deshija no tuvo un efecto significativo sobre la incidencia de la enfermedad. Lo anterior hace suponer que la deshija, práctica que se hace con cuchillo no es diseminadora de la enfermedad, situación que contradice lo argumentado por Solórzano et al. (2001) en el sentido de que el cuchillo y otras herramientas transmiten la "bacteriosis" cuando son trasladadas de un lote a otro.

Es de interés resaltar, el hecho de que los promedios de incidencia de bacteriosis observados en las diferentes distancias, tengan una correlación significativa con el daño por picudo en los tres años en los que se evaluó, esa correlación aumenta y es muy alta en la tercera evaluación realizada. Mora y colaboradores (2005), también destacan esa relación, comentando que la presencia de "picudos" es un evento general en todas las plantaciones que presentan este síndrome de la "bacteriosis" y plantean la hipótesis de que podría darse una infección en la planta de tipo vertical por la lluvia y en sentido horizontal entre plantas (a distancia) por insectos, posiblemente, "picudos". También Alpízar y colaboradores (s. f.) ya habían documentado que adultos de Metamasius hemipterus y Rynchophorus palmarun recolectados en plantación, fueron llevados a laboratorio en donde se les constató la presencia de Erwinia sp. y Pseudomonas sp. en su estilete.

\section{CONCLUSIONES}

1. Se observó un marcado efecto de la distancia de siembra entre plantas sobre el número de palmitos cosechados por parcela. Con una mayor distancia entre plantas (menor densidad) disminuyó la producción de palmitos y no hubo un efecto de la deshija sobre el número de palmitos producidos.
2. Los ingresos totales más altos se obtuvieron con la distancia de $0,25 \mathrm{~m}$ entre plantas (20.000 plantas/ha), con una diferencia positiva sobre las otras distancias $(0,50,0,75 \mathrm{y}$ $1,00 \mathrm{~m}$ ) de 20,27 y $39 \%$ respectivamente.

3. En el primer y tercer ciclo de evaluación $(2002,2004)$ se observó un efecto de la distancia de siembra sobre el porcentaje de cepas dañadas por picudo. Cuanto mayor fue la densidad, mayor fue el daño por picudo. En el 2003 la ausencia de deshija, también aumentó la incidencia de daño por "picudo".

4. La incidencia de "bacteriosis" fue diferente entre distancias en todos los tres ciclos (años) evaluados, en el 2004 fue más alta en las densidades mayores; y no se observó efecto de la deshija para esta variable.

5. Se obtuvo una correlación significativa entre la incidencia de daño por "picudo" y "bacteriosis" en las tres evaluaciones hechas en el 2002, 2003 y 2004, cuyo coeficiente de correlación ( $r$ ), fue relativamente bajo en el 2002, aumentó en el 2003 y fue muy alto en el año 2004.

Agradecimientos: El autor agradece el apoyo del Dr. Jorge Mora Urpí por sus consejos en la conducción del trabajo de campo y en la revisión del primer borrador de este artículo. También al Técnico José L. Rivera por su apoyo con parte del trabajo y evaluaciones, al inicio del trabajo de campo.

\section{LITERATURA CITADA}

Alpízar, D.; Fallas, M.; Oehlschager, A.; González, L. s. f. Captura masiva con trampas y feromona del picudo de la caña del oeste de la India (Metamasius hemipterus) y el picudo americano de la palma (Rhynchophorus palmarun) en palmito con espinas realizando deshija y no deshija. Informe en archivo técnico. E.E.L.D., M.A.G. Guápiles, Costa Rica. Mimeografiado, sin año, $10 \mathrm{p}$. 
Alpízar, D.; Fallas, M.; Oehlschager, A.; González, L. 2002. Pheromone mass trapping of the west Indian sugarcane weevil and the American palm weevil in palmito palm. Florida Entomologist 85 (3): 426-430.

Bogantes, A. 1996. Recomendaciones para la siembra y manejo de palmito de pejibaye (Bactris gasipaes B. K.). Estación Experimental Los Diamantes. Guápiles, Costa Rica. 12 p.

Bogantes, A.; Mora, J.; Arroyo, C. 1997. Densidades de siembra. In: Memoria Curso Nacional sobre palmito de pejibaye (Bactris gasipaes). San José, Costa Rica. Universidad de Costa Rica. 5 p.

; Agüero, R.; Mora, J. 2004. Palmito de pejibaye (Bactris gasipaes): Distancias de siembra y manejo de malezas. Agronomía Mesoamericana. 15 (2):185-192.

Chalá, V. 1991. Evaluación de ocho densidades de siembra de Bactris gasipaes H.B.K.para producción de palmito en la región amazónica ecuatoriana. In: IV Congreso internacional sobre Biología, Agronomía e Industrialización del Pijuayo. Editores: J. Mora, L. T. Szott, M. Murillo y V. Patiño. U.C.R. San José, Costa Rica. p. 255-265.

Fernández, B. s.f. El pejibaye. Serie de boletines. Boletín Técnico para el agricultor. Costa Rica. Proyecto ANAI. No. 3. p. 29.

King, A. B.; Saunders, J. L. 1984. Las plagas invertebradas de cultivos anuales alimenticios en América Central. TDRI, CATIE, Costa Rica. p. 84.

López, P. G.; López, P. J. 1995. Introducción al Micro-SAS: Aplicación al análisis de experimentos agrícolas. Unidad de Informática y Bioestadística. CATIE, Turrialba. Costa Rica. 119 p.
Mora, J. 1989. Densidades de siembra para producción de palmito. Universidad de Costa Rica. Serie técnica Pejibaye $1(1): 10-12$

. 1999. Morfología (cap 1). Variedades (cap 2). Prácticas agronómicas de la araña (cap 5). In: Palmito de pejibaye (Bactris gasipaes K.) su cultivo e industrialización. Editores J. Mora y J. Gainza. San José, Costa Rica. Editorial U.C.R. p. 32-114.

Mora U., J.; Sánchez, E.; Wang, A.; Uribe, L.; Pizarro, L.; Chaimsohn, P.; Vargas, L.; Bogantes, A.; Mesón, R.; Arroyo, C. 2005. Combate de la "bacteriosis" del palmito de pejibaye. Folleto técnico, CONICIT-UCR-INTA-PITTA PEJIBAYE. SIEDIN -UCR, Costa Rica. 22 p.

Norris, R.; Kogan, M. 2000. Interactions between weeds, arthropod pests, and their natural enemies in managed ecosystems. Weed Science 48:94-158.

Solórzano, A.; Vargas, L.; Mora, J. 2001. Bacteriosis del palmito para pejibaye (Bactris gasipaes k.), en la zona Atlántica de Costa Rica. Protección de Cultivos. D.I.A. Ministerio de Agricultura y Ganadería 1999-2000. Editores Jorge Mora B. y Arturo Solórzano A. San José, Costa Rica. p. 155-159.

Vargas, A. 1994. Evaluación de ocho densidades de siembra en pejibaye para palmito (Bactris gasipaes K.) en el Atlántico de Costa Rica. CORBANA 19 ( 42): 11-16.

. 2000. La palmera de pejibaye (Bactris gasipaes K.) y su cultivo en Costa Rica para la obtención de palmito. CORBANA, San José, Costa Rica. 67 p.

Zamora, C. 1984. Densidades de siembra de pejibaye para palmito con tallo simple y tallo doble. In: Sexto Informe de labores 1983-1984. ASBANA. P. 75-80. 